\title{
Penggunaan Media Hipnoterapi dalam Meningkatkan Kinerja Karyawan di STIKES Jendral Ahmad Yani Cimahi
}

\author{
Denok Sunarsi ${ }^{1 *}$, Achmad Setya Roswendi ${ }^{2}$, Udin Ahidin ${ }^{3}$, Asep Muhammad Lutfi ${ }^{4}$, \\ Waluyo Jati ${ }^{5}$, Ali Maddinsyah ${ }^{6}$ \\ ${ }^{1,2,3,4,5,6}$ Program Studi Manajemen, Fakultas Ekonomi, Universitas Pamulang \\ ${ }^{2}$ Sekolah Tinggi Ilmu Kesehatan Jenderal Achmad Yani \\ *Penulis Korespodensi: denoksunarsi@unpam.ac.id
}

\begin{abstract}
ABSTRAK
Tujuan diselenggarakannya kegiatan Pengabdian Kepada Masyarakat ini adalah untuk meingkatkan kinerja Karyawan pada STIKES AHMAD YANI ini. Dengan adanya hipnoterapi, mereka dapat memandanga pekrjaan dan situasi menjadi lebih baik. Hal layaknya menemukan permasalahan kemudian menemukan jalan keluar dengan mudah. Dengan memberikan pengalaman hal ini dapat menambah keilmuan mereka digabungkan dengan ilmu kedokteran, karena hakikatnya ilmu kedokteran terikat kuat dengan hipno. Menghilangkan fobis, analisis penyakit dan lain sebagainya. Dengan kemampuan ini mereka dapat meningkatkan motivasi kerja yang baik, solid dan berkualitas.

Kata Kunci :Hypnoterapi, Motivasi Kerja
\end{abstract}

\begin{abstract}
The purpose of this Community Service activity is to improve the performance of Employees at this AHMAD YANI STIKES. With hypnotherapy, they can see work and the situation for the better. It is like finding a problem then finding a solution easily. By providing experience this can add to their knowledge combined with medical science, because the essence of medical science is strongly bound by hypno. Eliminating phobis, disease analysis and so on. With this ability they can increase good work motivation, solid and quality.
\end{abstract}

Keywords: Hypnotherapy, Work Motivation

\section{PENDAHULUAN}

Pembangunan kesehatan di Indonesia saat ini diarahkan untuk mencapai "Indonesia Sehat 2010" dengan tujuan akhir terciptanya derajat kesehatan masyarakat yang optimal. Untuk dapat mencapai kondisi tersebut pendidikan merupakan langkah awal yang strategis untuk memulainya. Berangkat dari pertimbangan di atas, Yayasan Kartika Eka Paksi sebagai lembaga yang menyantuni bidang pendidikan merasa terpanggil untuk berpartisipasi dalam pembangunan bangsa melalui penciptaan sumber daya manusia di bidang kesehatan yang profesional dengan mendirikan lembaga pendidikan tinggi kesehatan, yaitu diantaranya Sekolah Tinggi Ilmu Kesehatan Jenderal Achmad Yani (Stikes Jenderal A.Yani) Cimahi.

STIKES Jendral Achmad Yani memiliki karyawan profesional dengan etos kerja 
Denok Sunarsi, dkk

yang rapi dan baik. Sebuah perusahaan akan berjalan dengan baik apabila memiliki tiga pondasi utama, yaitu sumber daya fisik, modal dan sumber daya manusia. Ketiga hal tersebut harus bersinergi agar dapat memperlancar laju operasional perusahaan dalam mencapai setiap tujuan yang direncanakan.

Sumber daya fisik merupakan berbagai jenis invetaris peralatan yang dibutuhkan untuk kegiatan operasional, sedangkan modal tentu saja dana yang dibutuhkan untuk memulai serta menjalankan roda perekonomian perusahaan. Terakhir, sumber daya manusia yang paling penting karena fungsinya untuk menggerakkan dua sumber daya lainnya. Sumber daya manusia terutama karyawan membutuhkan stimulus berkelanjutan agar tetap bisa menjalankan tugas-tugasnya dengan baik. dalam hal ini, motivasi kerja sangat dibutuhkan (Rismayadi \& Maemunah, 2016).

Tanpa motivasi, seorang karyawan tidak akan merasa antusias menyelesaikan pekerjaannya dan juga mudah putus asa apabila mengalami kegagalan (Fachreza, Musnadi, \& Majid, 2018). Pemimpin atau pemilik perusahaan harus peka terhadap kondisi ini karena lambat laun akan mempengaruhi seluruh kinerja organisasi sehing ga tujuan-tujuan sulit dicapai. Motivasi dapat diartikan sebagai suatu gairah, semangat dan kekuatan yang menggerakkan seseorang untuk bekerja. semakin tinggi motivasi yang dimiliki oleh orang tersebut, maka semakin baik kinerjanya (Mandey \& Sahangggamu, 2014). Ia juga akan lebih mudah menghadapi setiap kendala yang ada. Sebaliknya, saat motivasinya menurun, maka ia akan kehilangan performa dan semangat untuk tetap menghasilkan nilai positif dalam pekerjaannya.

Pemimpin yang bijak adalah mereka yang juga mengerti dengan kondisi dan kebutuhan karyawan yang bekerja di bawahnya (Badu \& Djafri, 2017). Atasan seharusnya tidak hanya memprioritaskan masalah pencapaian tujuan tetapi juga lebih peka terhadap keadaan SDA karena bagaimanapun merekalah yang menggerakkan setiap ide dan rencana yang telah disusun. Tanpa karyawan, maka ide-ide kreatif tidak akan dapat dijalankan dan perusahaan tidak akan mendapatkan keuntungan yang diharapkan.

\section{METODE PELAKSANAAN}

Kegitan Pengabdian Masyarakat ini dilaksanakan pada hari Selasa 14 April 2020 s/d Kamis, 16 April 2020

Metode pelaksanaan program pengabdian kepada masyarakat sebagai berikut:

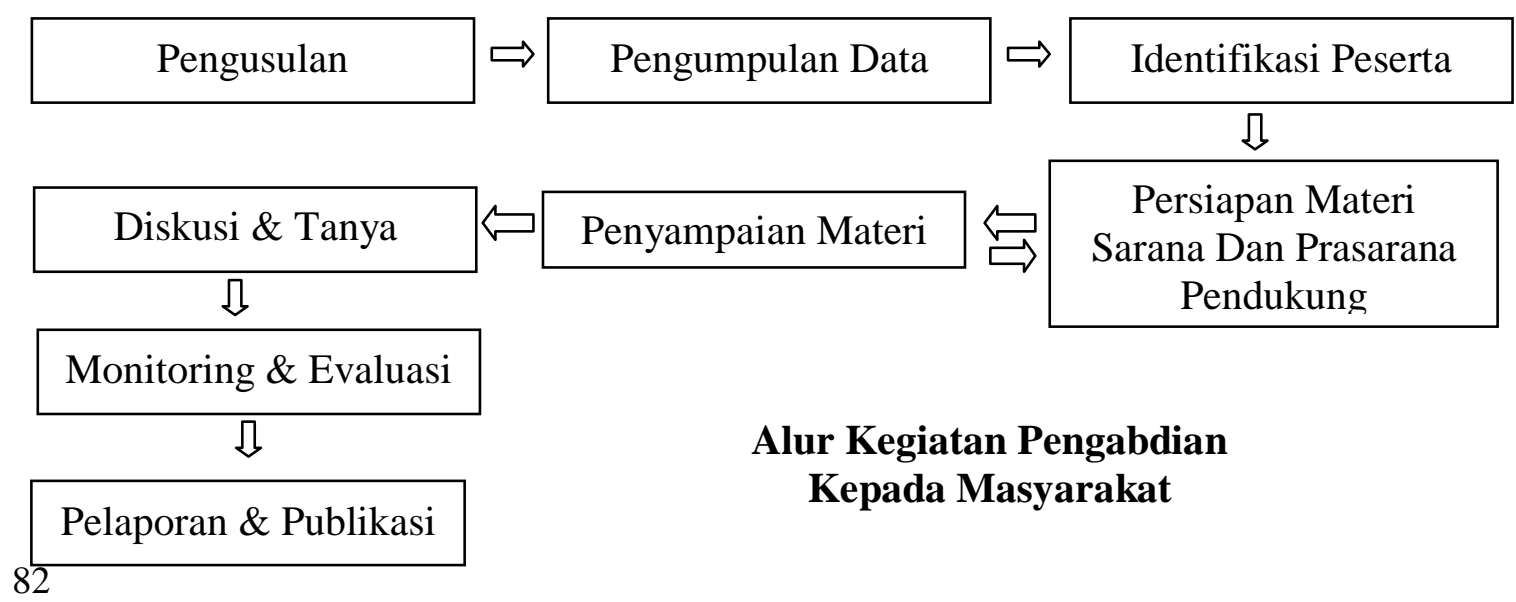




\section{HASIL DAN PEMBAHASAN}

Dalam mengatasi masalah yang diuraikan diatas, metode yang digunakan dengan menggunakan implementasi hipnoterapi. Hipnotherapi adalah terapi yang dilakukan pada subjek dalam kondisi Hipnosis. Kata "Hipnosis" adalah kependekan dari istilah James Braid's (1843) "neuro-hypnotism", yang berarti "tidurnya sistem saraf". Orang yang terhipnotis menunjukan karakteristik tertentu yang berbeda dengan yang tidak, yang paling jelas adalah mudah disugesti. Hipnotherapi sering digunakan untuk memodifikasi perilaku subjek, isi perasaan, sikap, juga keadaan seperti kebiasaan disfungsional, kecemasan, sakit sehubungan stress, manajemen rasa sakit, dan perkembangan pribadi.

Teknik terapi hipnosis (Hypnotherapy) yang didefinisikan sebagai suatu kondisi pikiran dimana fungsi analitis logis pikirandireduksi sehingga memungkinkan individu masuk ke dalam kondisi bawah sadar (sub-conscious/unconscious), di mana tersimpan beragam potensi internal yang dapat dimanfaatkan untuk lebih meningkatkan kualitas hidup. Individu yang berada pada kondisi "hypnotic trance" lebih terbuka terhadap sugesti dan dapat dinetralkan dari berbagai rasa takut berlebih (phobia), trauma ataupun rasa sakit. Individu yang mengalami hipnosis masih dapat menyadari apa yang terjadi di sekitarnya beri kut dengan berbagai stimulus yang diberikan oleh terapis.

Terapi hypnosis (hypnotherapy) kini merupakan fenomena ilmiah, namun hingga kini masih belum terdapat definisi yang jelas, bagaimana sebenarnya mekanisme kerja hypnotherapy. Beberapa ilmuwan berspekulasi bahwa hipnotherapi menstimulir otak untuk melepaskan neurotransmiter, zat kimia yang terdapat di otak, encephalin dan endhorphin yang berfungsi untuk meningkatkan mood sehingga dapat mengubah penerimaan individu terhadap sakit atau gejala fisik lainnya.

Sementara menurut Profesor John Gruzelier, seorang pakar psikologi di Caring Cross Medical School, London, guna menginduksi otak dilakukan dengan mem provokasi otak kiri untuk non aktif dan memberikan kesempatan kepada otak kanan untuk mengambil kontrol atas otak secara keseluruhan. Hal ini dapat dilakukan dengan membuat otak fokus pada suatu hal secara monoton menggunakan suara dengan intonasi datar (seolah-olah tidak ada hal penting yang perlu diperhatikan).

Secara umum mekanisme kerja hypnotherapy sangat terkait dengan aktivitas otak manusia. Aktivitas ini sangat beragam pada setiap kondisi yang diindikasikan melalui gelombang otak yang dapat diukur menggunakan alat bantu EEG (Electroenchepalograph). Berikut diuraikan berbagai gelombang otak disertai dengan aktivitas yang terkait:

a. Beta $(14-25 \mathrm{~Hz})$ (normal); Atensi, kewaspadaan, kesigapan, pemahaman, kondisi yang lebih tinggi diasosiasikan dengan kecemasan, ketidaknyamanan, kondisi lawan/lari

b. Alpha (8 - $13 \mathrm{~Hz})$ (meditatif); Relaksasi, pembelajaran super, fokus relaks, kondisi trance ringan, peningkatan produksi serotonin, kondisi pra-tidur, meditasi, awal mengakses pikiran bawah sadar (unconscious)

c. Theta $(4-7 \mathrm{~Hz})$ (meditatif); Tidur bermimpi (tidur REM/Rapid Eye Movement), peningkatan produksi catecholamines (sangat vital untuk pembelajaran dan ingatan), peningkatan kreatifitas, pengalaman emosional, berpotensi terjadinya perubahan 
Denok Sunarsi, dkk

sikap, peningkatan pengingatan materi yang dipelajari, hypnogogic imagery, meditasi mendalam, lebih dalam mengakses pikiran bawah sadar (unconscious).

d. Delta $(0,5 \quad-\quad 3 \mathrm{~Hz}) \quad$ (tidur dalam); Tidur tanpa mimpi, pelepasan hormon pertumbuhan, kondisi non fisik, hilang kesadaran pada sensasi fisik, akses ke pikiran bawah sadar (unconscious) dan memberikan sensasi yang sangat mendalam ketika diinduksi dengan Holosinc

\section{PENUTUP}

Pelaksanaan kegiatan pengabdian masyarakat oleh lembaga penelitian dan pengembangan masyarakat (LPPM) Universitas Pamulang yang dilakukan oleh dosendosen program studi Pendidikan Ekonomi dan Manajemen telah berjalan dengan lancar dan mendapat sambutan hangat dari tempat pelaksanaan kegiatan ini yaitu di STIKES UNJANI. Dengan ada kegiatan ini menjadikan kemudahan karyawan dalam memberikan sugesti dan motivsi diri untuk dapat lebih yakin dalam membangun rasa percaya diri dalam dirinya

Selama kegiatan berlangsung peserta penyuluhan memberikan tanggapan yang sangat baik, hal ini dapat dilihat dari dukungan dan atusiasme mereka dalam setiap kegiatan yang diadakan.

Selain itu harapan kami dengan pengabdian ini dapat membuka wawasan dari para anggota karang taruna, sehingga tidak hanya memberikan tambahan pengetahuan tetapi juga dapat diterapkan khususnya dalam menerapkan kemampuan berorganisasi. Selain itu diharapkan kemudahan karyawan dalam memberikan sugesti dan motivsi diri untuk dapat lebih yakin dalam membangun rasa percaya diri dalam dirinya.

\section{DAFTAR PUSTAKA}

Badu, S. Q., \& Djafri, N. (2017). Kepemimpinan dan Perilaku Organisasi. Kepemimpinan dan Perilaku Organisasi.

Fachreza, Musnadi, S., \& Majid, M. S. A. (2018). Pengaruh Motivasi kerja, lingkungan

kerja, dan budaya organisasi terhadap kinerja karyawan dan dampaknya pada

kinerja Bank Aceh Syariah di Kota Banda Aceh. Jurnal Magister Manajemen.

Gunawan, A. W. (2012). Hypnotherapy The Art of Subconscious Restructuring: PT Gramedia Pustaka Utama.

Hajar, Ibnu. (2012). Hypnoteaching. Memaksimalkan Hasil Proses Belajar-Mengajar Dengan Hipnoterapi. Yogyakarta: DIVA Press.

Hakim, A. (2011). Dahsyatnya Pikiran Bawah Sadar: VisiMedia.

Mandey, S., \& Sahangggamu, P. (2014). PENGARUH PELATIHAN KERJA,

MOTIVASI, DAN DISIPLIN KERJA TERHADAP KINERJA KARYAWAN

PADA PT. BANK PERKREDITAN RAKYAT DANA RAYA. Jurnal Riset

Ekonomi, Manajemen, Bisnis Dan Akuntansi.

https://doi.org/10.35794/emba.v2i4.6359

Rismayadi, B., \& Maemunah, M. (2016). Pengaruh Motivasi Kerja, Kepemimpinan dan

Budaya Organisasi Terhadap Kepuasan Kerja Karyawan serta Dampaknya pada

Kinerja Perusahaan (Studi kasus pada PT. Concord Indonesia). Jurnal Manajemen \& Bisnis Kreatif. https://doi.org/10.36805/manajemen.v2i1.181 
Sunarsi, D. (2019). The Analysis of The Work Environmental and Organizational Cultural Impact on The Performance and Implication of The Work Satisfaction. Jurnal Ilmiah Ilmu Administrasi Publik, 9(2), 113-122.

Sunarsi, D. (2018). Pengaruh Motivasi Dan Disiplin Terhadap Produktivitas Kerja Karyawan Pada PT. Nadi Suwarna Bumi. Jurnal Semarak, 1(1).

Sunarsi, D. (2018). Analisis Motivasi Kerja Tenaga Pendidik Sukarela Pada Pusat Kegiatan Belajar Masyarakat (PKBM) Bimasda Kota Tangerang Selatan. Kreatif: Jurnal Ilmiah Prodi 